\title{
Análise da prevalência de casos de sarampo no município de Marabá, Estado do
}

\section{Pará, Brasil}

\author{
Analysis of the prevalence of measles cases in the Municipality of Maraba, State of Pará, Brazil \\ Análisis de la prevalencia de casos de sarampión en la municipio de Maraba, Estado de Pará, Brasil
}

Recebido: 02/02/2022 | Revisado: 10/02/2022 | Aceito: 21/02/2022 | Publicado: 03/03/2022

\author{
Lucas Moreira Rodrigues \\ ORCID: https://orcid.org/0000-0001-5449-098X \\ Universidade do Estado do Pará, Brasil \\ E-mail: lucasmrodrigues@outlook.com \\ Daniela Soares Leite \\ ORCID: https://orcid.org/0000-0002-3412-1375 \\ Universidade do Estado do Pará, Brasil \\ E-mail: danielaleite@uol.com.br
}

\begin{abstract}
Resumo
O sarampo é uma doença infecciosa aguda de etiologia viral comum em crianças e que pode evoluir com complicações severas. O objetivo da atual pesquisa é analisar a prevalência do sarampo e correlacionar isto com a cobertura vacinal para a doença, no município de Marabá, Estado do Pará, no período de 2019 a 2020. Foi conduzido um estudo epidemiológico retrospectivo, descritivo, com abordagem analítica. Foram utilizados dados secundários disponíveis na Secretaria de Saúde do município de Marabá e Sistema de Informação de Agravos de Notificação (SINAN). Foram encontrados um total de 113 casos de saraeitompo no município de Marabá entre 2019 e 2020. Houve uma predominância dos casos de sarampo entre menores que um ano e entre 20 a 34 anos, o sexo mais frequente foi o masculino e a escolaridade mais frequente foi ensino médio completo. Quanto a cobertura vacinal, observou-se uma tendência de decrescimento entre os anos de 2000 a 2020. Deve-se intensificar as campanhas de vacinação no Município de Marabá com estratégias específicas para atingir os grupos com maiores incidências de sarampo, com o objetivo de inibir a transmissão do vírus.
\end{abstract}

Palavras-chave: Sarampo; Epidemiologia; Cobertura vacinal.

\begin{abstract}
Measles is an acute infectious disease of viral etiology that is common in children and can develop into severe complications. The objective of the current research is to analyze the prevalence of measles and to correlate this with the vaccination coverage for the disease, in the municipality of Marabá, State of Pará, from 2019 to 2020. A retrospective, descriptive epidemiological study with an analytical approach was conducted. Secondary data available from the Health Department of the municipality of Marabá and the Information System for Notifiable Diseases (SINAN) were used. A total of 113 measles cases were found in the municipality of Marabá between 2019 and 2020. There was a predominance of measles cases among children younger than one year and between 20 and 34 years old, the most frequent sex was male and the most frequent schooling was complete high school. As for vaccination coverage, a downward trend was observed between the years 2000 and 2020. Vaccination campaigns in the Municipality of Marabá should be intensified with specific strategies to reach the groups with the highest incidences of measles, with the objective of inhibiting the transmission of the virus.
\end{abstract}

Keywords: Measles; Epidemiology; Vaccination coverage.

\section{Resumen}

El sarampión es una enfermedad infecciosa aguda de etiología viral que es común en niños y que puede progresar a complicaciones graves El objetivo de la presente investigación es analizar la prevalencia del sarampión y correlacionarla con las coberturas de vacunación para la enfermedad, en el municipio de Marabá, Estado de Pará, de 2019 a 2020. Se realizó un estudio epidemiológico retrospectivo, descriptivo, con enfoque analítico. Se utilizaron datos secundarios disponibles de la Secretaría de Salud del municipio de Marabá y del Sistema de Información de Enfermedades de Declaración Obligatoria (SINAN). Foram encontrados um total de 113 casos de sarampo no município de Marabá entre 2019 e 2020. Houve uma predominância dos casos de sarampo entre menores que um ano e entre 20 a 34 anos, o sexo mais frequente foi o masculino e a escolaridade mais frequente foi completado la escuela secundaria. En cuanto a las coberturas de vacunación, se observó una tendencia a la baja entre los años 2000 y 2020. Se deben intensificar las campañas de vacunación en el Municipio de Marabá con estrategias específicas para llegar a los grupos con mayor incidencia de sarampión, con el objetivo de inhibir la transmisión de la enfermedad. virus.

Palabras clave: Sarampión; Epidemiología; Cobertura de vacunación. 


\section{Introdução}

O sarampo é uma doença infecciosa aguda de etiologia viral que tem como causador o vírus do sarampo (Measles morbilivirus). Esférico, ele é característico por possuir um invólucro de ácido ribonucleico (RNA) e cadeia simples e polaridade negativa, sendo integrante da família Paramyxoviridae do gênero Morbilivirus (Brasil, 2019). Extremamente contagioso, o sarampo é muito comum em crianças e um dos seus maiores riscos é a possibilidade de evolução com complicações severas (a exemplo de encefalites, pneumonias e óbitos). Seu processo de infecção provoca uma vasculite generalizada que é responsável por desencadear diversas manifestações clínicas (Carvalho et al., 2019).

Sua transmissão é dada de forma direta (de indivíduo para indivíduo), através da propagação de secreções nasofaríngeas liberadas em situações de tosses, espirros, fala e também no processo de respiração de uma pessoa eventualmente infectada pelo vírus. De forma menos comum, é possível também ocorrer o processo de transmissão por pequenas partículas em suspensão no ar (aerossol) em membranas do trato respiratório superior ou conjuntiva (Carvalho et al., 2019). Ela ocorre de quatro a seis dias antes de surgirem exantemas e quatro a seis dias após o surgimento (Brasil, 2019).

Ainda não existem tratamentos específicos para a cura do sarampo, sendo feito apenas o acompanhamento de suporte para o infectado. Tal acompanhamento é importante para evitar a evolução da doença, bem como do desenvolvimento de infecções secundárias no indivíduo. Imediatamente após o diagnóstico positivo para sarampo, a Organização Mundial de Saúde (OMS) recomenda a administração de Vitamina A, com reforços especiais para pacientes com carências da mesma. Em casos de infecções oportunistas, antibióticos podem ser administrados. Já em casos mais graves da doença, em que podem haver interação com o sistema nervoso central (SNC), podem ser utilizados o interferon alfa e a riboflavina (Santos, 2019).

A principal forma de controle epidemiológico do sarampo é por meio da vacinação. Em território brasileiro, através do Programa Nacional de Imunizações (PNI), é preconizada a cobertura vacinal de $95 \%$ de toda a população e em todos os municípios, a fim de se interromper a cadeia de transmissão pela eliminação dos suscetíveis: os não imunizados (Carvalho et al., 2019).

No Brasil a imunização contra o sarampo se iniciou de forma sistemática nos anos 70 após a implantação do PNI(Fiocruz, 2014). Em 2001 já não havia mais a transmissão autóctone (que se origina da região onde é encontrado) do vírus no país, sendo os registros de casos posteriores originários de outros genótipos, importados de outros países e continentes. Devido ao relativo sucesso do PNI em barrar a cadeia de transmissão do sarampo, em 2016 o Brasil recebeu da Organização Mundial da Saúde (OMS) o certificado de eliminação da circulação do vírus, declarando as Américas livre da doença (Moraes et al., 2020).

Entretanto, esta eliminação da circulação não garantia que, no país, pessoas não pudessem ser infectadas pelo vírus. Novos casos também podem ser atribuídos a uma importação do vírus por pessoas que estiveram em localidades endêmicas e trouxeram consigo o patógeno (Xavier et al., 2019). Não obstante, em 2018, novos casos de sarampo foram reportados em algumas regiões brasileiras, inclusive no Estado do Pará e em 2019 o Brasil perdeu a condecoração da OMS de eliminação da circulação do sarampo (Brasil, 2019).

A partir desta problemática e pelo fato de o Estado do Pará ter sido recorrente no registro de novos casos do sarampo nos últimos anos no Brasil, este trabalho propõe-se a analisar a prevalência da doença no município de Marabá e correlacionar isto com a cobertura vacinal para a doença, em 2019 e 2020, fornecendo subsídios numéricos para que os órgãos competentes possam agir com maior afinco na busca do controle dos casos de sarampo em Marabá. Nos anos anteriores ao recorte proposto na pesquisa não foram registrados nenhum caso de sarampo desde que se instituiu o Sistema de Informação de Agravos de Notificação (SINAN) em 1993. 


\section{Metodologia}

Estudo epidemiológico retrospectivo, descritivo, com abordagem analítica. Os dados a respeito do número de vacinas e número de casos de sarampo entre os anos de 2019 e 2020 foram colhidos a partir do Departamento de Vigilância em Saúde vinculado à Secretaria de Saúde do município de Marabá.

Os dados secundários disponibilizados foram tabulados no software Excel® e apresentados por meio de tabelas e gráficos. As variáveis (idade, sexo e escolaridade, seguindo as classes contidas nas fichas) foram apresentadas por meio de frequências relativas e absolutas. No gráfico de cobertura vacinal foi traçada uma linha de tendência linear dos dados por meio do Excel®. A taxa de incidência anual do sarampo foi calculada a partir do número de casos da doença registrados no período de 2019 a 2020, dividido pelo número total da população, obtido por meio do IBGE multiplicado por 100.000.

A presente pesquisa seguiu os preceitos da Declaração de Helsinque e do Código de Nuremberg e foi aprovada pelo Comitê de Ética em Pesquisa em seres humanos da Universidade do Estado do Pará (UEPA), campus VIII/Marabá, conforme a resolução 466/12 do Conselho Nacional de Saúde, que trata de pesquisa envolvendo seres humanos, sob número do parecer 4.790.177/2021. CAAE: 47622621.0.0000.8607. A pesquisa também obteve autorização, por escrito, da Secretária Municipal de Saúde de Marabá para coletar dados sobre a vigilância epidemiológica do sarampo no município de Marabá.

\section{Resultados}

Foram notificados um total de 113 casos de sarampo no município de Marabá entre 2019 e 2020. A caracterização dos casos de sarampo no município de Marabá foi descrita na Tabela 1.

Tabela 1 - Características epidemiológicas dos casos de Sarampo em Marabá, PA. (n=113).

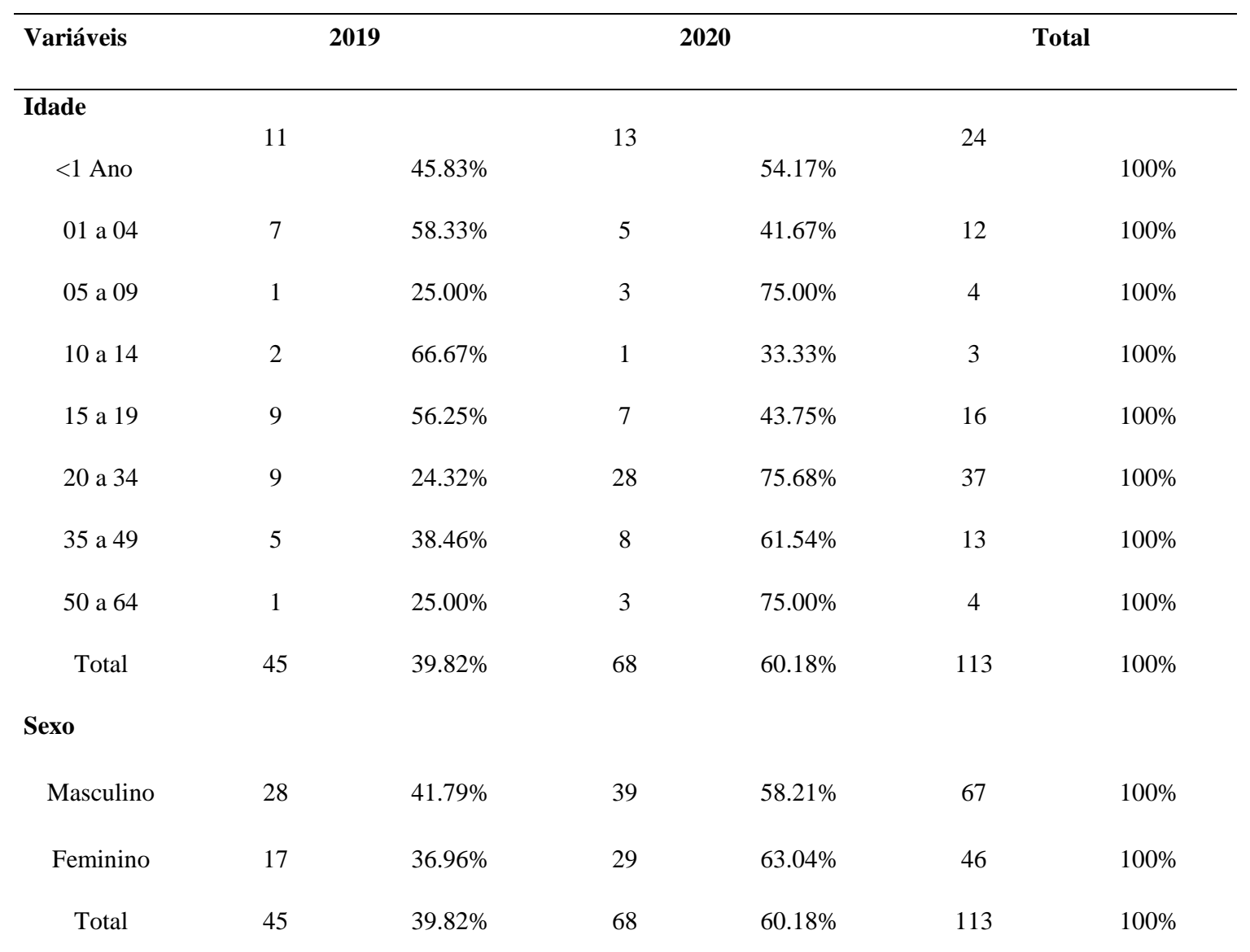




\section{Escolaridade}

\begin{tabular}{|c|c|c|c|c|c|c|}
\hline Branco & 4 & $22.22 \%$ & 14 & $77.78 \%$ & 18 & $100 \%$ \\
\hline $\begin{array}{l}1^{\mathrm{a}} \text { a } 4^{\mathrm{a}} \text { série } \\
\text { incompleta }\end{array}$ & 6 & $50.00 \%$ & & $50.00 \%$ & 12 & $100 \%$ \\
\hline $4^{\mathrm{a}}$ série & 1 & $33.33 \%$ & 2 & $66.67 \%$ & 3 & $100 \%$ \\
\hline $\begin{array}{l}5^{\mathrm{a}} \text { a } 8^{\mathrm{a}} \text { série } \\
\text { incompleta }\end{array}$ & 0 & $0.00 \%$ & 7 & $100.00 \%$ & 7 & $100 \%$ \\
\hline $\begin{array}{c}1^{\mathrm{a}} \text { a } 8^{\mathrm{a}} \\
\text { completos }\end{array}$ & 2 & $66.67 \%$ & 1 & $33.33 \%$ & 3 & $100 \%$ \\
\hline $\begin{array}{l}\text { Ensino médio } \\
\text { incompleto }\end{array}$ & 6 & $40.00 \%$ & 9 & $60.00 \%$ & 15 & $100 \%$ \\
\hline $\begin{array}{c}\text { Ensino médio } \\
\text { completo }\end{array}$ & 7 & $41.18 \%$ & 10 & $58.82 \%$ & 17 & $100 \%$ \\
\hline $\begin{array}{l}\text { Educação } \\
\text { superior } \\
\text { incompleta }\end{array}$ & 1 & $50.00 \%$ & 1 & $50.00 \%$ & 2 & $100 \%$ \\
\hline Não se aplica & 18 & $50.00 \%$ & 18 & $50.00 \%$ & 36 & $100 \%$ \\
\hline Total & 45 & $39.82 \%$ & 68 & $60.18 \%$ & 113 & $100 \%$ \\
\hline
\end{tabular}

Fonte: Secretaria Municipal de Saúde de Marabá (SMS) (2021).

De acordo com a Tabela 1, os casos se concentraram na faixa etária de 20 a 34 anos, que contabilizou 37 (32,74\%) casos de sarampo, seguido pela faixa etária <1 ano que somou 24 (21,24\%) casos. O sexo mais frequente foi o masculino, com 67 $(59,29 \%)$ da amostra. Quanto a escolaridade, 54 (47,78\%) não possuíam esse dado, por estarem no grupo "não se aplica" ou no "branco". Dos registros que possuíam essa informação, o grupo que fez o ensino médio completo predominou, com 17 (15,04\%) casos, seguido pelo grupo que possui o ensino médio incompleto $15(13,27 \%)$ casos.

A Tabela 2 sintetiza as principais informações da incidência do sarampo no município de Marabá desde o primeiro relato da doença em 2019.

Tabela 2 - Prevalência do Sarampo e número de vacinas aplicadas contra o Sarampo entre 2019 a 2020 no município de Marabá-PA. (N=113).

\begin{tabular}{ccccc}
\hline Ano & Casos de Sarampo & População estimada & Incidência/100.000hab & Vacinas aplicadas \\
\hline $\mathbf{2 0 1 9}$ & 45 & 279349 & 16,10 & 23802 \\
$\mathbf{2 0 2 0}$ & 68 & 283542 & 23,98 & 36728 \\
Total & 113 & - & - & 60530 \\
\hline
\end{tabular}

Fonte: Secretaria Municipal de Saúde de Marabá (SMS), 2021 / IBGE: Estimativas da População (2021). 
De acordo com a Tabela 2, houveram 45 casos de sarampo em 2019 e 68 casos em 2020. A taxa de incidência estimada de sarampo aumentou de 16,10 casos por 100 mil habitantes em 2019 para 23,98 casos por 100 mil habitantes em 2020. Houve também um aumento do número de vacinas aplicadas contra o sarampo, que aumentou de 23.802 vacinas, para 36.728 vacinas aplicadas.

A Figura 1 descreve o comportamento temporal da cobertura vacinal contra o sarampo no município de Marabá de 2000 a 2020 .

Figura 1 - Cobertura vacina contra o Sarampo em porcentagem para a população alvo entre 2000 e 2020.

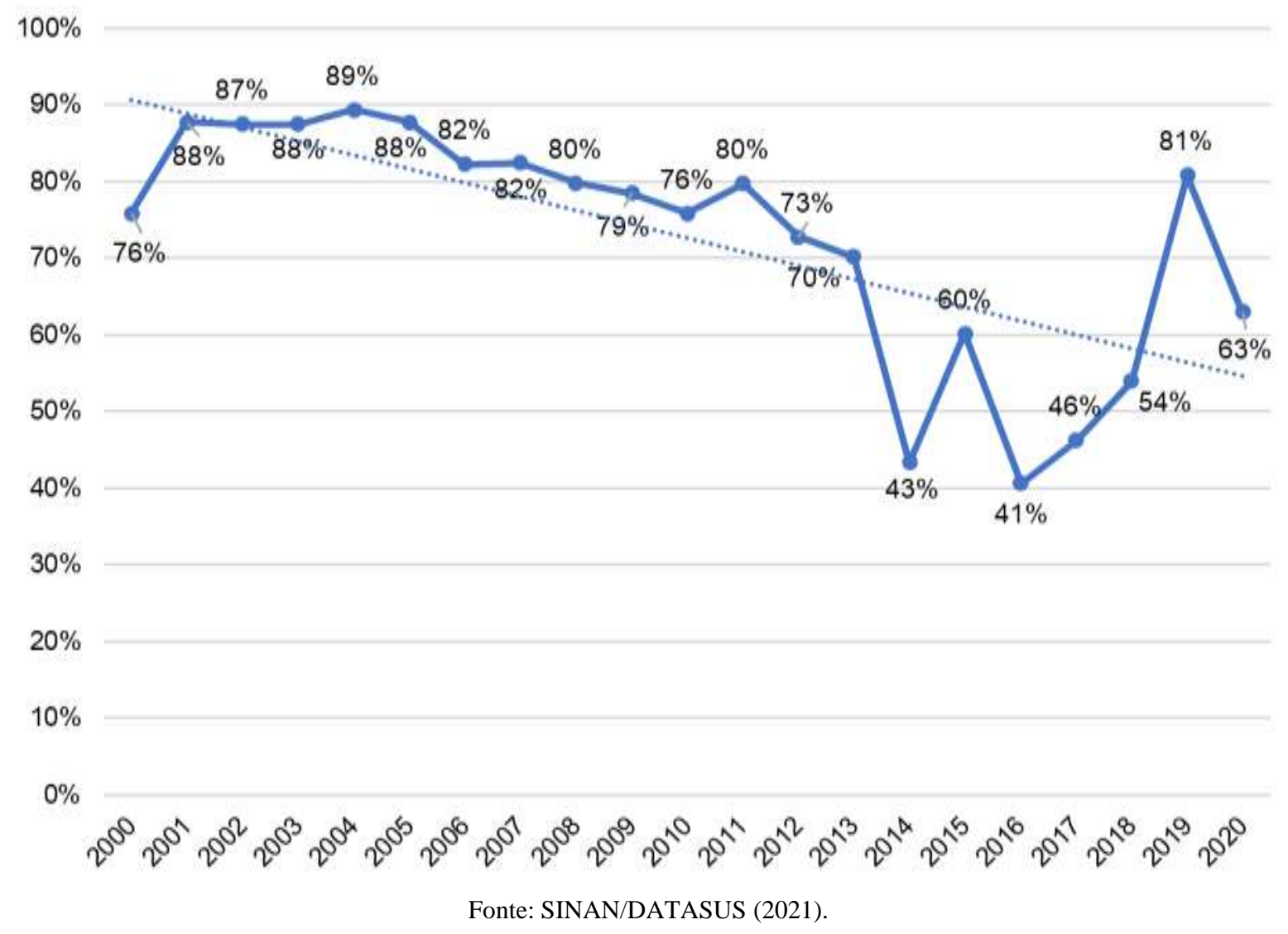

De acordo com a Figura 1 pode ser observar que os anos com maior cobertura vacinal são 2004, 2003 e 2005 respectivamente com $89 \%, 88 \%$ e $88 \%$. Uma queda substancial da cobertura vacinal foi observada nos anos de 2016,2014 e 2017, respectivamente com $41 \%, 43 \%$ e $46 \%$. A tendência da série temporal, representada pela linha pontilhada, demonstra uma queda da cobertura vacinal entre os anos estudados.

\section{Discussão}

O presente estudo identificou uma predominância dos casos de sarampo entre menores que um ano e entre 20 a 34 anos e o sexo mais frequente foi o masculino. A taxa de incidência de sarampo cresceu de 16,10 em 2019 para 23,98 casos em 100 mil habitantes em 2020. O número de vacinas aplicadas contra o Sarampo também aumentou entre os dois anos analisados, passando de 23802 para 36728 entre 2019 e 2020. Observou-se uma tendência de decrescimento da cobertura vacinal entre os anos de 2000 a 2020.

Quanto a faixa etária mais acometida pelo sarampo, um estudo a nível nacional identificou uma distribuição semelhante 
ao encontrado no presente estudo, com três picos de incidência, o primeiro em menores de um ano, que contabilizou 234 casos (38,6\%), o segundo entre 1 e 4 anos, com 124 casos $(20,4 \%)$ e o terceiro entre 20 a 34 anos, com $83(13,6 \%)$ dos casos de sarampo entre 2007 e 2014 (Almeida et al., 2020). O boletim epidemiológico dos casos de sarampo feito pelo Ministério da Saúde em março de 2020 também possui resultados semelhantes, com as faixas etárias mais acometidas sendo entre 20 a 29 anos (33,0\% dos casos) e menores que um ano (19,6\% dos casos), com a diferença de que a faixa etária de 15 a 19 anos (17,4\% dos casos) se tornou a terceira mais acometida (Brasil, 2019)

É importante ressaltar que o esquema vacinal para o sarampo recomendado pelas sociedades brasileiras de Pediatria (SBP) e de Imunizações (SBIm) são de duas doses de vacina, preferencialmente entre 12 a 15 meses de idade, sendo contraindicada em indivíduos menores de um ano (Sociedade Brasileira de Imunologia, 2020). Dessa forma, presume-se que atingir a cobertura vacinal adequada em outras faixas etárias, sobretudo na população entre 20 a 29 anos, seja o principal meio de barrar a transmissão para os indivíduos menores de um ano, que além de não receberem a vacinação, também são mais suscetíveis a complicações e óbitos pelo sarampo (Rodrigues et al., 2020).

Diversos estudos epidemiológicos apontam que a incidência de sarampo no Brasil parece ser maior no sexo masculino que no sexo feminino (Brasil, 2019; Poethko-Müller et al., 2011; Silvério, 2019). Apesar de não haver um consenso na literatura, alguns estudos propõem que o sexo feminino frequenta mais os Postos de Saúde, sobretudo no pré-natal e puerpério, onde são constantemente conscientizadas sobre doenças infectocontagiosas e a importância da vacina para evita-las (Silvério, 2019). Outra hipótese para explicar a predominância masculina nos casos de sarampo é a de que no momento de implantação das vacinas SR (sarampo e rubéola) e SCR (sarampo, caxumba e rubéola - tríplice viral) foi priorizado a população feminina em idade fértil para diminuir a incidência de rubéola em gestantes, promovendo uma maior cobertura vacinal feminina (Poethko-Müller \& Mankertz, 2011).

A taxa de incidência de sarampo no município de Marabá ainda é alta quando comparada a nível nacional. De acordo com o boletim epidemiológico até a $32^{\circ}$ semana epidemiológica de 2020 a média da taxa de incidência no Brasil era de 10,25 casos por 100 mil habitantes (BRASIL, 2020). Se comparada aos Estados da federação, a taxa de incidência do município de Marabá só fica atrás do Estado do Pará (91,15/100 mil habitantes), Mato Grosso do Sul (54,19/100 mil habitantes) e Maranhão (32,54/100 mil habitantes) no ano de 2020 (BRASIL, 2020).

As principais explicações para o reaparecimento de grandes surtos de sarampo no Brasil se relacionam com a importação de casos e com a diminuição da cobertura vacinal (Rodrigues et al., 2020). A importação de casos de sarampo é associada principalmente ao movimento migratório da Venezuela, que resultou no aparecimento de surtos inicialmente nos Estados de Amazonas, Roraima e Pará, e que depois se distribuiu por todo Brasil. Além do rastreamento dos casos, outro dado que apoia a hipótese de importação do sarampo da Venezuela é que o tipo viral identificado nos surtos brasileiros é principalmente o subtipo D8, o mesmo que circula na Venezuela (Brasil, 2019; Lima et al., 2020).

Entretanto, a importação de casos de sarampo não resultaria em grandes surtos se a imunização nacional alcançasse a meta de 95\% de cobertura vacinal estipulada pelo Ministério da Saúde (Rodrigues et al., 2020). O presente estudo identificou que no município de Marabá, embora houvesse um crescimento do número de vacinas aplicadas a partir de 2019, a cobertura vacinal para o sarampo nunca alcançou a meta de 95\% do Ministério da Saúde, iniciando uma diminuição na cobertura, sobretudo, a partir de 2014, o que possivelmente formou grupos de pessoas não imunizadas facilitando a ocorrência de surtos (Jesus et al., 2015).

Um dos fatores que podem explicar a diminuição da cobertura vacinal nos últimos anos é que o sucesso do Programa Nacional de Imunização e a certificação de erradicação de sarampo pela OMS em 2015 possa ter dado uma sensação de falsa segurança ao país, o que pode ter influenciado na diminuição e na baixa adesão das campanhas vacinais (Leite et al., 2019) Fatores socioeconômicos também podem influenciar na adesão da população a campanhas vacinais. Alguns fatores associados 
a baixa adesão da vacinação infantil para o sarampo são baixo nível de escolaridade materna, saneamento, nutrição, dificuldade de locomoção aos serviços de saúde, gestação na adolescência, gestação não planejada e gestações com pré-natal insuficiente (Rocha et al., 2015).

A adesão vacinal também é influenciada pelo crescimento do movimento antivacina, que tem se tornado cada vez mais frequente e persuasivo nos últimos anos. Tal movimento é caracterizado pela disseminação de notícias falsas que imitam informações científicas e que tentam refutar ou colocar em dúvida a eficácia e segurança das vacinas (Aps et al., 2018). Especificamente com relação a vacina tríplice viral informações falsas disseminadas nos meios digitais brasileiros a relacionaram com a incidência de síndrome do espectro autista em crianças (Vasconcellos-Silva et al., 2015). A repercussão do movimento antivacina foi agravada pela pandemia da COVID-19, aumentando ainda mais o risco de uma menor adesão em futuras campanhas vacinais.

\section{Considerações Finais}

Foi identificada uma maior incidência de sarampo em pessoas que possuíam entre 20 a 34 anos, do sexo masculino e que completou o ensino médio. O número de vacinas aumentou em resposta ao surto de sarampo que se iniciou em 2019 no município de Marabá, entretanto nos anos anteriores a cobertura vacinal estava muito abaixo da taxa de cobertura estipulada pelo Ministério da Saúde. Ressalta-se a importância da intensificação de campanhas de vacinação no Município de Marabá, sobretudo com o objetivo de aumentar a cobertura vacinal sobre os adultos de 20 a 34 anos que não foram vacinados previamente e com estratégias que possibilitem uma maior adesão do público masculino, como visitas domiciliares em horários não comerciais.

O presente estudo apresenta algumas limitações por se utilizar de um banco de dados secundários da Secretaria Municipal de Saúde de Marabá, que abrange apenas informações fornecidas pela rede pública de saúde. Além disso, os casos que são subnotificados podem superestimar os dados no Sistema Único de Saúde, de tal forma que diminui a precisão das informações coletadas com a realidade.

\section{Referências}

Almeida, C. C. da C., Carvalho, G. B., Ferreira, J. de S., Souza, L. V. G., Fé, M. de S. M., Fontenele, A. P. da S., Oliveira, L. krystina R. de, \& Rodrigues, A. C. E. (2020). Estudo epidemiológico de pacientes infectados por sarampo no Brasil / Epidemiological study of patients infected by spam in Brazil. Brazilian Journal of Health Review, 3(2), 1513-1526. https://doi.org/10.34119/BJHRV3N2-015

Aps, L. R. de M. M., Piantola, M. A. F., Pereira, S. A., de Castro, J. T., Santos, F. A. de O., \& Ferreira, L. C. de S. (2018). Eventos adversos de vacinas e as consequências da não vacinação: uma análise crítica. Revista de Saúde Pública, 52. https://doi.org/10.11606/S1518-8787.2018052000384

Brasil. (2019, March 19). Situação do Sarampo no Brasil - $2018 \quad a \quad 2019 . \quad$ Brasília: Ministério Da Saúde. https://antigo.saude.gov.br/images/pdf/2019/marco/19/Informe-Sarampo-n37-19mar19aed.pdf

BRASIL. (2020, June 22). Vigilância epidemiológica do sarampo no Brasil $\quad$ - 2020 : $\quad$ semanas epidemiológicas $1 \quad$ a 32. https://antigo.saude.gov.br/images/pdf/2020/August/31/Boletim-epidemiologico-SVS-34.pdf

Carvalho, A. L. de, Dorabela, A., Andrade, J. G., Diniz, L. M. O., \& Romanelli, R. M. de C. (2019). Sarampo: atualizações e reemergência. 29(0), S80-S85. https://doi.org/10.5935/2238-3182.20190084

Fiocruz. (2014). Mudando a história: parcerias alteraram a situação do sarampo no país. https://www.bio.fiocruz.br/index.php/br/noticias/811-mudando-ahistoria-parcerias-alteraram-a-situacao-do-sarampo-no-pais

Jesus, H. S. de, Nascimento, G. L., Rosa, F. M., \& Santos, D. A. dos. (2015). Investigação de surto de sarampo no Estado do Pará na era da eliminação da doença no Brasil. Cadernos de Saúde Pública, 31(10), 2241-2246. https://doi.org/10.1590/0102-311X00017515

Leite, F. S. L. da S., Ramalho, M. I. L., \& Sousa, M. N. A. de. (2019). EVOLUÇÃO DO SARAMPO NO ESTADO DE RORAIMA E A ATUAL SITUAÇÃO VACINAL NO BRASIL. Revista Ciência e Desenvolvimento, 12(1), 129-140. https://doi.org/10.11602/1984-4271.2019.12.1.8

Lima, G. T., Brito, A. G. de, Vargas, G. L. M., Ferreira, J. D., Silva, P. I. de O., Segundo, J. T. M., \& Couto, B. C. (2020). Os impactos da mudança do perfil epidemiológico do sarampo no Brasil. Brazilian Journal of Health Review, 3(3), 5973-5981. https://www.brazilianjournals.com/index.php/BJHR/article/view/11258

Moraes, M. M. de, Sagica, F. do E. S., Jesus, M. I. de, Medeiros, R. L. F. de, Silva, D. de F. L. da, Matos, H. J. de, Nunes, H. M., Rodrigues, S. G., Moraes, M. M. de, Sagica, F. do E. S., Jesus, M. I. de, Medeiros, R. L. F. de, Silva, D. de F. L. da, Matos, H. J. de, Nunes, H. M., \& Rodrigues, S. G. (2020). Estudo 
Research, Society and Development, v. 11, n. 3, e45011326444, 2022

(CC BY 4.0) | ISSN 2525-3409 | DOI: http://dx.doi.org/10.33448/rsd-v11i3.26444

soroepidemiológico do sarampo em populações residentes na Região Metropolitana de Belém, estado do Pará, Brasil, 2016 a 2018. Revista Pan-Amazônica de Saúde, 11. https://doi.org/10.5123/S2176-6223202000378

Poethko-Müller, C., \& Mankertz, A. (2011). Sero-epidemiology of measles-specific IgG antibodies and predictive factors for low or missing titres in a German population-based cross-sectional study in children and adolescents (KiGGS). Vaccine, 29(45), 7949-7959. https://doi.org/10.1016/J.VACCINE.2011.08.081

Rocha, H. A. L., Correia, L. L., Campos, J. S., Silva, A. C., Andrade, F. O., Silveira, D. I., Machado, M. M., Leite, Á. J., \& Cunha, A. J. L. A. (2015). Factors associated with non-vaccination against measles in northeastern Brazil: Clues about causes of the 2015 outbreak. Vaccine, 33(38), 4969-4974. https://doi.org/10.1016/J.VACCINE.2015.07.027

Rodrigues, B. L. P., Souza, L. R. de, Soares, N. M. dos S., Silva, K. de N. S. da, \& Júnior, A. F. C. (2020). Atualizações sobre a imunização contra o sarampo no Brasil: uma revisão sistemática. Revista Eletrônica Acervo Saúde, 55, e3919-e3919. https://doi.org/10.25248/REAS.E3919.2020

Santos, P. R. M. (2019). Sarampo: desde a prevenção ao tratamento. Algum dia alcançaremos a erradicação? Sarampo: Desde a Prevenção Ao Tratamento. Algum Dia Alcançaremos a Erradicação? https://estudogeral.sib.uc.pt/handle/10316/88382

Silvério, S. M. R. (2019). Perfil epidemiológico do Sarampo na região norte brasileira no ano de 2018. http://repositorio.uniceub.br/jspui/handle/prefix/13646

Sociedade Brasileira de Imunologia. (2020, August 26). Prorrogação da estratégia de vacinação contra o sarampo para a população de 20 a 49 anos de idade - SBIm. https://sbim.org.br/informes-e-notas-tecnicas/11-outras-entidades/1335-ms-svs-prorrogacao-da-estrategia-de-vacinacao-contra-o-sarampo-para-apopulacao-de-20-a-49-anos-de-idade-26-08-2020

Vasconcellos-Silva, P. R., Castiel, L. D., \& Griep, R. H. (2015). A sociedade de risco midiatizada, o movimento antivacinação e o risco do autismo. Ciência \& Saúde Coletiva, 20(2), 607-616. https://doi.org/10.1590/1413-81232015202.10172014

Xavier, A. R., Rodrigues, T. S., Santos, L. S., Lacerda, G. S., \& Kanaan, S. (2019). Diagnóstico clínico, laboratorial e profilático do sarampo no Brasil. Jornal Brasileiro de Patologia e Medicina Laboratorial, 55(4), 390-401. https://doi.org/10.5935/1676-2444.20190035 